\title{
Research on the Cultivation Model of Diversified Application Talents for Broadcasting and Television Directors Based on Cloud Network Platform
}

\author{
Nan $\mathrm{Li}^{1 *}$, Xiaoxu Chen ${ }^{2}$ \\ ${ }^{1}$ School of Lecturer, Weifang Engineering Vocational College, Shandong, China, 262500 \\ ${ }^{2}$ School of Assistant, Weifang Engineering Vocational College, Shandong, China, 262500
}

\begin{abstract}
In recent years, Internet has developed rapidly. The original mode of cultivating talents for radio and television directors in our undergraduate colleges no longer satisfy the needs of the current society. The talents cultivated in colleges and universities cannot match the talents needed by society. Many college students are facing graduation and unemployed, and employers are also worried about that they cannot find suitable talents. In order to adapt to the development of the society, the teaching method of the radio and television director major must be reformed. Based on the original theoretical basic knowledge, it is necessary to strengthen the students' data analysis and practical skills, they should assess the current situation and absorb excellent domestic and foreign students in the curriculum configuration. Cultivate experience, but it must conform to the current situation in our country.
\end{abstract}

\section{Introduction}

Since entering the 21 st century, our government has attached great importance to propaganda work and the training of media talents. Higher film and television arts education receive extensive attention. Many film and television art schools have been opened in China. In the more than ten years after the "Catalogue of Undergraduate Programs in Ordinary Colleges and Universities" revised in 1998, radio and television directors develop rapidly, Only from 2011 to 2012, a total of 47 colleges and universities opened the radio and television editing majors. According to incomplete statistics, as of the end of 2013, nearly 100 schools have opened this major, and the employment direction of radio and television directors is very wide, as shown in Figure 1. However, in recent years, the Ministry of Education has strengthened the report restriction and management of this profession, and the broadcasting and television editing and directing profession has been saturated with employment, and the supply and demand sides cannot fully connect.[1].

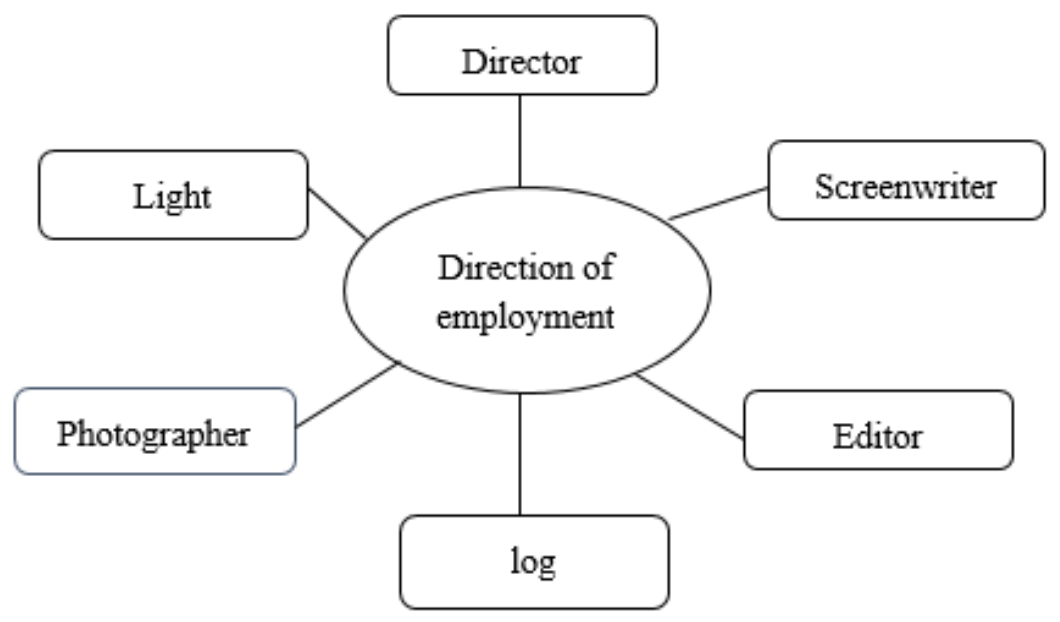

Figure 1. Direction of employment

*Corresponding author e-mail: youzhaoshanhui@163.com 
Since 2012, big data has become a hot word in all walks of life. Someone vividly compares that in the era of big data, the data generated by a family is equivalent to a Beijing library. For big data, now people do not define it as a concept, but will describe it as a social state. In the era of big data, we can not only obtain the information we need from big data, but also use big data. To complete the statistics of information and the prediction of social conditions. In the era of big data, everyone is inseparable from data and is also covered by data. Whoever has data resources and who has the ability to process and analyze data will be in a dominant position in society. In the era of big data, all walks of life are facing tremendous impacts. As the frontier industries of information dissemination, radio and television are facing unprecedented impacts and challenges. The promulgation of the World "Data Journalism Award" in 2012 caused a huge shock in the media industry[2]. The reform and reshaping of the industry will inevitably lead to the reform of the academic circle. If the timeliness and urgency of the reform are lacking, it will inevitably lead to a disconnect between the supply and demand sides, leading to the failure of college journalism education. Teachers majoring in radio and television editing and directing in colleges and universities should fully realize that this is a rare opportunity. It is an urgent task to adapt to the needs of the big data era, change the existing talent training model, and cultivate diversified applicationoriented talents in radio and television editing and directing that meet the requirements of the times[3].

\section{Cultivation of data literacy of directors in the era of big data}

The radio and television editing and directing major is a highly practical and applicable major. The radio and television editing and directing majors in local universities emphasize the cultivation of hands-on ability. The core concept of talent training has two aspects: "editing" and "directing". "Editing" mainly focuses on the preliminary work of radio and television creation, and mainly refers to the creative planning, collection and writing of scripts, etc. of radio and television programs. It requires a certain degree of editing and writing skills. "Directing" mainly refers to the mid- and late-stage work of radio and television programs, generally including collection, editing, shooting, production, and synthesis. It can be seen that the talents trained by the radio and television director major must have the ability to operate in actual work, but also have the ability to control the program as a whole; they must have the artistic literacy for the construction of video storytelling, but also have a comprehensive humanistic literacy. The promulgation of the World "Data Journalism Award" in 2012 brought a huge impact to the media, changed the traditional communication concept of radio and television, and further deepened the trend of media integration. The cultivation of professional talents for radio and television directors must lead the way in the era of big data and cultivate radio and television directors who meet the needs of the times[4].

\subsection{The ability to guide public opinion from big data analysis}

In the past three years, Weibo, especially WeChat, has swept across. The emergence of this kind of social media has promoted the emergence and rapid dissemination of a large amount of information. At the same time, it has gradually formed a situation in which social media widely disseminates information and mainstream media continue to correct deviations. People find that some organizations and individuals in social media will draw conclusions through data mining and analysis, and disseminate them quickly. This information will have a greater impact on society. However, the authoritative correction function of mainstream media is irreplaceable by any other social media. In the era of big data, how the media represents, dominates, and influences public opinion is an important task for media data analysts. Radio and television directors must have the ability to plan programs, grasp themes, and guide public opinion. Grasping the direction of public opinion and political sensitivity of the program is the key to training the professional ability of radio and television directors.

\subsection{Sensitive analysis capabilities of "information prediction" and "information early warning"}

In the Internet age, some valuable information predictions are possible because of the support of data. Data analysts can analyze and process group data to complete accurate predictions beyond the scope of human experience[5]. This includes not only the prediction of natural events but also the early warning of social events. In the era of big data, people's behavior patterns, psychological activities, interpersonal communication and topic attention can be provided as effective data to data analysts, and any time and any topic can be used as the object of analysis. Track everyone's dynamics on Weibo and WeChat to perceive the emotions of the entire group of society. In this case, perform emotion mining and opinion mining, and perceive social emotions through the capture and analysis of these big data. The results can not only predict the content of topics, but also predict the development of events and possible behaviors. The ability of data analysts to predict, warn, and judge public opinion is an important link in the training of professional talents in broadcast and television directors.

\section{Further reform the curriculum}

Media professionals working in a network environment should have the ability to collect, analyze and integrate big data. The rise of data journalism puts forward higher requirements for media professionals, especially radio and television media professionals. However, the academia's attention and research on big data has only just begun[6]. The radio and television editing and directing majors of local universities should be renewed according to the needs and development of today's 
society. Construct a knowledge structure and related curriculum to meet the urgent needs of the industry. Radio and television directors must fully realize that the work they are engaged in is not only art itself, but also use traditional scientific methods and advanced communication technology to effectively spread the content. However, the current status quo is that radio and television director education is basically positioned according to the art education model, and the traditional education model neither recognizes the position nor truly completes the discipline construction[4]. The training of application-oriented talents only stays in the editing of audio and video and the simple use of technical equipment. The meaning and content of the education of radio and television directors are vague, and the curriculum is mostly imitated between schools. In the era of big data, the curriculum of $\mathrm{J}$ and Yibo TV should be reformed in the new environment, new technology and new demand. Incorporate relevant courses for the cultivation of applied talents into the core courses.

\subsection{Add data information courses}

At present, the major courses of radio and television editing and directing in colleges and universities are not placed in the center[7]. Generally, information technology courses and computer application courses are the main courses of information processing. Mainly learn the skills of information acquisition, processing, editing, and transmission, as shown in Figure 2. In media work, media professionals must complete the collection and processing of news information in the era of big data, and need to find reliable scientifically based information from a huge database for sorting and dissemination. The existing information technology courses are difficult to meet the needs of the industry. The future radio and television communication is digital news communication supported by information technology. The traditional skills of collecting, writing, photographing, recording, and editing are facing the impact and challenge of big data. In the era of big data, radio and television media professionals interview databases rather than interviewers, and the ability to apply big data has become an important skill for radio and television media professionals. Western media have required reporters to be able to screen out valuable news topics from the huge data, sort out news stories from the data, and predict and gain insight into the hidden phenomena behind the data. It is hard to imagine how radio and television directors who don't know how to use computers and networks, and don't use big data technology, can accomplish related tasks. Only by proficiently mastering data application skills and possessing certain data analysis and processing capabilities can we meet the needs of current media development and complete radio and television editing tasks quickly, efficiently and accurately[8].

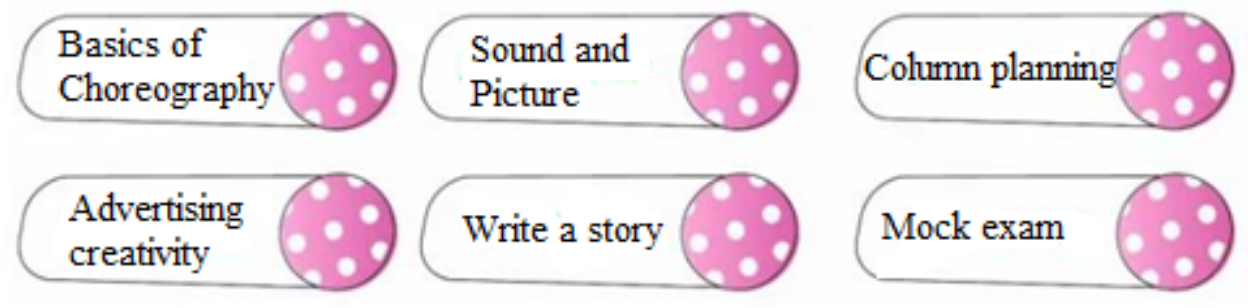

Figure 2. Radio and TV Directing Course

Nowadays, information technology and computer application are only used as basic courses of general education in the undergraduate course group of radio and television editing and directing in colleges and universities, accounting for a small proportion of credits. Society needs to be proficient in two or more computer professional knowledge, proficient in two or more professional operation skills, and be able to achieve creative results and breakthrough progress in the overlap and overlap of multiple knowledge and multiple skills. Talent. In the future professional courses, it is necessary to supplement and strengthen the professional skills courses of information technology, and make data screening, data analysis, data visualization operations and other capabilities as important content for the training of data literacy in radio and television editing. The training of compound and diversified talents is the goal of the training of broadcast and television directors.

\subsection{Learning from mature foreign curriculum setting experience}

Professor Zhu Jianhua from the School of Media and Communication of the City University of Hong Kong summed up four paths for American universities to offer professional digital journalism courses, which we can learn from and use. The first is the case-oriented production-oriented teaching, which focuses on: digital narration; 3D animation; interactive games. The second is case-oriented analytical teaching, whose curriculum focuses are: digital research; digital humanities; digital ethics. The third is data-oriented production-oriented teaching[9]. The curriculum focuses on: data visualization; data storage; information graphic design. The fourth is data-oriented analytical teaching. The focus of the course is: data mining; social network analysis; website analysis. Among these four paths, the data production type is more worthy of reference for the professional courses of domestic colleges and universities radio and television directors. However, the problem also arises, namely the problem of teachers. The 
representative universities in the United States mentioned above have been recruiting teachers with relevant academic backgrounds for the past 10 years. Our colleges and universities are now not only encountering the problems of curriculum reform, but also teacher training and introduction have become an urgent problem[10].

\section{Conclusion}

In the era of big data, the TV director team is very different from the traditional way of operation. The current team presents the characteristics of efficient and capable work. The competition of current social news is the data analysis ability and the keen news capture ability. An important position requires strong operational and thinking skills in today's society. . In the current teaching environment, it is not enough. The television director major should open up channels with various disciplines such as information technology, computer, and management, and complete the practical integration of multiple disciplines. The Internet is developing rapidly, but our country's awareness of the reform of the profession of television directors is very shallow, and it is still in the initial stage. At present, the key problem is how to quickly change the existing teaching methods. In the development of data literacy education, the knowledge structure can be updated in a timely and effective manner to make up for the deficiencies of the current teaching situation. Adapt to the changes in the new communication environment and cultivate diversified application-oriented choreographers who adapt to the development of the times.

\section{References}

1. Yu Suping. The development of e-commerce is an inevitable trend in the business activities of iron and steel enterprises [J]. China E-commerce,2010:18-19.
2. Yan Qi. Discussion on the Cultivation Mode of Practical Talents for Radio and TV Writers and Directors [J]. Urban Construction Theory Research (Electronic Edition),2018:209.

3. Li Nan. Analysis on the Cultivation Mode of Applied Talents for Radio and TV Writers and Directors $[\mathrm{J}]$. Human Resources Development,2017:226-226.

4. Jin Can. Research on Teaching Reform of Radio and TV Directing under the Cultivation Mode of Applied Talents [J]. China High-tech Zone,2018:100.

5. Dong Ke. Analysis on the Cultivation of Practical Talents for Radio and TV Writers and Directors [J]. Popular Arts and Art,2013:245.

6. Zhou Mengying. Research on the Cultivation Model of Radio and TV Writer and Director in the Financial Media Era [J]. Western Radio and Television,2019:184-185.

7. Xing Limei. Research on the Cultivation Mode of Diversified Applied Talents for Radio and TV Writers and Directors in the Era of Big Data [J]. Journal of Changzhou Institute of Technology: Social Science Edition,2014:110-114.

8. Li Nan. Analysis on the Cultivation Mode of Applied Talents for Radio and TV Writers and Directors $[\mathrm{J}]$. Human Resources Development,2017:226-226.

9. Wang Lili. Research on the Cultivation Model of Radio and TV Writers and Directors in the New Media Era [J]. Intelligence, 2014:193.

10. Wu Jun, Xue Lilei. Research on the Cultivation Mode of Diversified Applied Talents for Broadcasting and Hosts in the Era of Media Convergence [J]. Journal of Science: Early Ten,2018: 14-15. 